\title{
Preparation and Characterization of Natural Nano Hydroxyapatite from Eggshell and Seashell and Its Effect on Bone Healing
}

\author{
Banan N. Alhussary, Ghada A. Taqa,* Amer A. Taqa \\ Department of Dental Basic Sciences, College of Dentistry. University of Mosul, Mosul, Iraq. \\ *Corresponding authors E-mail: ghada.abd.taqa@gmail.com
}

\begin{abstract}
The Objectives of the present study were undertaken to prepared hydroxyapatite powder from eggshell and seashell and convert them in Nano size. Hydroxyapatite (HA) is a biomaterial with osteoconductive properties and is prepared by the precipitation method. The properties of HA can be enhanced when the material is synthesized in the Nanoscale range to use in the mandibular bone of the rabbit to examine the influence of (HA) on bone healing.The eggshell and seashell were cleaned, and the phosphoric acid was added. The product inserts in the oven then calcined at $700^{\circ} \mathrm{C}$ for 1 hour in the muffled furnace to evaporate $\mathrm{CO}_{2}$ and to get the white crystalline powder, which indicated the presence of HA, this powder was converting to nanoparticle by attraction method. The product was applied in the groove of the rabbit's mandibular bone after surgical procedures to show the bone healing in histological examination. The results of IR Spectroscopy for the eggshell and seashell hydroxyapatite powder showed that the two compounds showed the same IR spectrum and the location of bands is approximately the same in the two compounds compared with the commercial hydroxyapatite powder by using FT-IR spectroscopy after dried at $100^{\circ} \mathrm{C}$. Histologically show that eggshell and seashell hydroxyapatite powder accelerated the bone healing in the mandibular bone of the rabbits. It can be concluded that, hydroxyapatite nanoparticles can successfully be produced by chemical precipitation techniques from eggshells and seashells with a phosphoric acid solution. Eggshell and seashell hydroxyapatite powder was used successfully in bone healing
\end{abstract}

Keywords: Eggshell, FTIR, hydroxyapatite, nanoparticles, Seashell.
Original Article:

DOI:HTTPS://DX.DOI.ORG/10.2160 8/JAVS.2020.85567

Received:05 Feb., 2020

Accepted : 15 March, 2020

Published: April, 2020

This is an open access article under the term of the Creative Commons Attribution 4.0 (CCBY) International License . To view a copy of this license, visit http://creativecommons.org/licen $\underline{\text { ses/by/4.0/ }}$

J. Appl. Vet Sci., 5(2 ):25-32.

\section{INTRODUCTION}

Bone is a specialized form of connective tissue that, like other connective tissues, consists of cells and extracellular matrix. It can be divided into compact bone tissue and spongy bone tissue. Unlike different connective tissue types, the extracellular matrix of bone tissue is mineralized, which makes it hard (Nanci, 2017). The mineral is calcium phosphate in the form of hydroxyapatite crystals $\left[\mathrm{Ca}_{10}\left(\mathrm{PO}_{4}\right)_{6}(\mathrm{OH})_{2}\right]$ (Tron, 2016).

Calcium phosphate has been used in the form of artificial bone. This has been synthesized and used for manufacturing various forms of implants, as well as for solid or porous coatings on other implants. Calcium phosphate can be crystallized into salts such as hydroxyapatite and $\beta$-whitlockite depending on the calcium to phosphate $(\mathrm{Ca}: \mathrm{P})$ ratio, presence of water, impurities, and temperature (PARK, 2003). Hydroxyapatite is the merging most biomedical, which is widely used in various biomedical applications, mainly in dentistry (Maha, 2019).

Hydroxyapatite (HAP) having chemical formula $\mathrm{Ca}_{10}\left(\mathrm{PO}_{4}\right)_{6}(\mathrm{OH})_{2}$ is the main chemical component of vertebral bone tissue consistently about (70\%) of the mineral phase of bone structure (Khandelwal, 2016). Hydroxyapatite powders can be produced by the two different sources of starting materials in two categories: Synthetic and natural (biologic) hydroxyapatite (Mezahi et al, 2011). HAP can be produced from coral seashells, eggshells, and also from body fluids, numerous methods have been reported for the preparation of hydroxyapatite from eggshells (Ripamonti et al., 2009). 
Eggshells are a better source of calcium for calcium oxide, calcium carbonate, calcium hydroxide, calcium phosphate, or hydroxyapatite (eHA), in comparison to other sources such as carbonaceous rock, precipitated soil, teeth, and bone, and crab or shrimp shells, also The main component of eggshell is calcium carbonate, which is more porous than limestone (Tangboriboon et al, 2012). The word seashell is often used to mean only the shell of a marine mollusk. Marine mollusk shells that are familiar to beachcombers and thus most likely to be called "seashells" are the shells of marine species of bivalves (or clams), gastropods (or snails), scaphopods (or tusk shells), polyplacophorans (or chitons), and cephalopods (such as nautilus and spirula).

Hydroxyapatite can either be synthesized from the natural organic-based materials or inorganic components. The traditional way of obtaining synthetic HA is working with expensive reagent chemicals; those synthetic routes are costly and time-consuming (Szcześ et al., 2017). Natural HA is believed to have better metabolic activity and a more dynamic response to the environment than the synthetic (Fara et al., 2015). Different methods have been used for the preparation of HA powders rely upon the technique; materials with various morphology, stoichiometry, and level of crystallinity have been obtained (Anchana and Priya, 2016).

\section{MATERIALS AND METHODS}

\section{Chemical study}

\section{Laboratory Synthesis of Egg Shell Hydroxyapatite}

The eggshell hydroxyapatite used in this study had been prepared manually from raw eggshells, The uncrushed eggshells were taken in bulk and cleaned with deionized water, and their surface was mechanically cleaned to remove the internal crust lining the shell $100 \mathrm{gm}$. of dried eggshells was burn at $900^{\circ} \mathrm{C}$ for 1 hour in the muffled furnace to removing $\mathrm{CO}_{2}$ (equation 1) and getting the white crystalline powder. Correct molar ratio needed for phosphoric acid solution $98 \%$ was added to $\mathrm{CaO}$ at $24 \mathrm{hr}$. A vigorous reaction happened with large foam (equation 2)(Figure 1.A). Washing with deionized water, then the precipitate was filtered through paper and left for $48 \mathrm{hr}$. at room temperature. The precipitation was kept in the oven for 30 minutes at $100^{\circ} \mathrm{C}$ for drying. Nanoparticles of Hydroxyapatite nHA were prepared by attrition methods described by (Claudio, 2005).

$$
\begin{aligned}
& \mathrm{CaCO} 3(\mathrm{~S}) \stackrel{900 \mathrm{C}^{\circ}}{\longrightarrow} \mathrm{CaO}+\mathrm{CO} 2(\mathrm{G}) \quad \text { (Eq.1) } \\
& 3 \mathrm{Ca}(\mathrm{OH}) 2+2 \mathrm{H} 3 \mathrm{PO} 4 \longrightarrow \mathrm{Ca} 3(\mathrm{PO} 4)_{2}+6 \mathrm{H} 2 \mathrm{O} \text { (Eq.2) }
\end{aligned}
$$

\section{Laboratory Synthesis of seashell Hydroxyapatite}

Seashell Hydroxyapatite preparation. The seashell hydroxyapatite used in this study had been prepared manually from snail sea shell and using the same method for preparation from eggshell (Figure 1.B). Bacteriological evaluation at zero, 2 days, 3 days, 4 days, 6 days, 8 days and 9 days of storage.
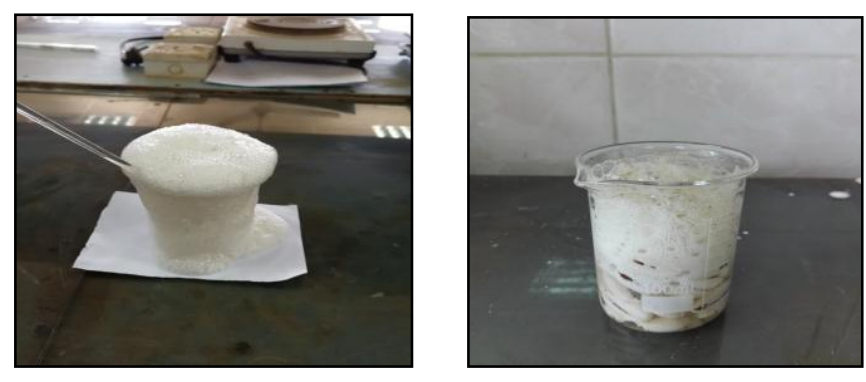

Figure 1(A, B): preparation of Eggshell HA and sea shell

\section{Estimation by chemical test (Silver nitrate Test )}

This test is done by added silver nitrate on the three forms of Hydroxyapatite(eggshell, seashell, and control H.A) to know this compound ortho or di or metaphosphorous by the color of precipitation that formed (Clarence, 1964) Depending on the method of preparation different crystal forms of silver phosphate can be produced of the same lattice structure the reaction can be used to know the biocompatibility of orthophosphate (Dorozhkin, 2009).

\section{Infrared Spectroscopy}

The prepared nHA from eggshell and seashell were characterized by using the FTIR-Alfa-Bruker spectrophotometer (Germany) in the region (500-4000 $\left.\mathrm{cm}^{-1}\right)$. This measurement was carried out at the University of Mosul, College of dentistry, Iraq.

\section{Experimental Animals}

Sixteen clinically healthy local male rabbits, 46 months-old, weighted $(1-1.5 \mathrm{Kg})$ were used in this study. A case sheet containing the rabbits' number, weight, the dose of anesthesia, date of operation, and date of sacrifice was recorded for each rabbit. The study was carried at the chemistry and pharmacology laboratory of the department of dental basic science.

\section{Surgical Procedure}

General anesthesia was achieved using a mixture of an intramuscular injection of ketamine (40 $\mathrm{mg} / \mathrm{kg})$ and xylazine $(8 \mathrm{mg} / \mathrm{kg})$ and waiting for a few minutes until the rabbit loses its consciousness. The rabbit then laid down in the left lateral position on the operating table; the hair was removed from the animal 's submandibular area using an electric hair clipper and rubbed with povidone-iodine as an antiseptic.

After the animals had been anesthetized within 5 minutes, A small incision (about $5 \mathrm{~cm}$ in length) was made in the skin over the submandibular area running with the lower border of the mandible starting from the symphysis area extended posteriorly along the inferior 
border of the mouth by using surgical blade No.153surgery was obtained with sterile scientific technique.

Blunt dissection was reflected in the periosteal, and themandibular bone was exposed. Small groove $(2 \mathrm{~mm}$ in diameter and $6 \mathrm{~mm}$ depth) was drilled in the heavy-duty dental engine of the low-speed handpiece by using $2.3 \mathrm{~mm}$ round carbide bur.

Profuse irrigation with distilled water. The bony defects were dried from blood with cotton pellets. The groove was filled with nanoparticles hydroxyapatite carried by small spoon excavator and condensed using amalgam condenser. The wound closed with 3.0 black silk suture using simple interrupted technique and rinsed with povidone-iodine $4 \%$. The aluminum numbering tag was placed in the rabbit ear for identification.

According to material filled in grooves, animals were divided into the following groups:

1- Group 1:serve as the control group consisted of 4 rabbits, with no treatment. This group was sacrificed after (30) days.

2- Group 2: standard Nano hydroxyapatite group consists of 4 rabbits; this group was sacrificed after (30) days.
Group 3: Eggshell Nano hydroxyapatite group consists of 4 rabbits; this group was sacrificed after (30) days.

Group 4: Seashell Nano hydroxyapatite group consists of 4 rabbits; this group was sacrificed after (30) days.

\section{Histological Procedures}

Sacrificed was performed after (30) days postoperatively for each group successively. Bone formation was evaluated histologically by a histopathologist. The bony mandibles were dissected from the head and immediately immersed in formalin $10 \%$ solution for fixation. Sectioned by a microtome $(4 \mu \mathrm{m}$ thick) and stained by hematoxylin and eosin. Then histopathological examination assessed the degree of healing reached at different time intervals and compared the results of using different biomaterials. The regeneration process of a bone injury occurs using different steps, including the development of granulation tissue, combined with the differentiation of osteoprogenitor cells and osteoblasts, which are responsible for bone matrix deposition (Cacchioli $\boldsymbol{e t}$ al., 2006)

\section{RESULTS}

\section{Infrared Spectroscopy Estimation of Important Bands}

\subsection{Estimation of Hydroxyapatite Bands}

The results showed that the prepared nHA is the $\alpha$-orthophosphate type which is biocompatible to human use (Figure 2).

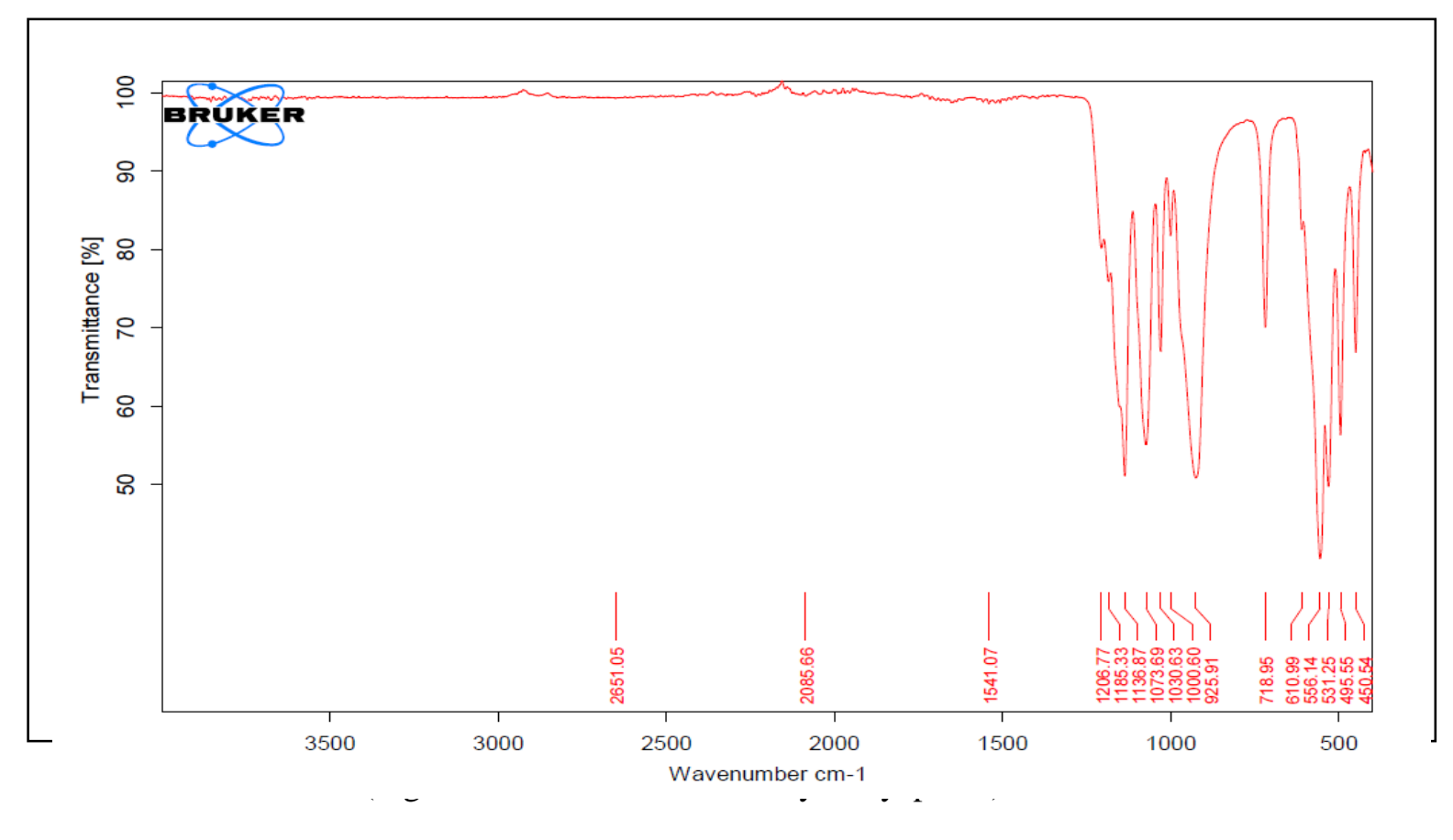




\subsection{Estimation of eggshell and seashell bands}

The spectrum of the synthetic eggshell ( Figure 3) and seashell (Figure 4) bands showed similar results to those obtained for the standard hydroxyapatite

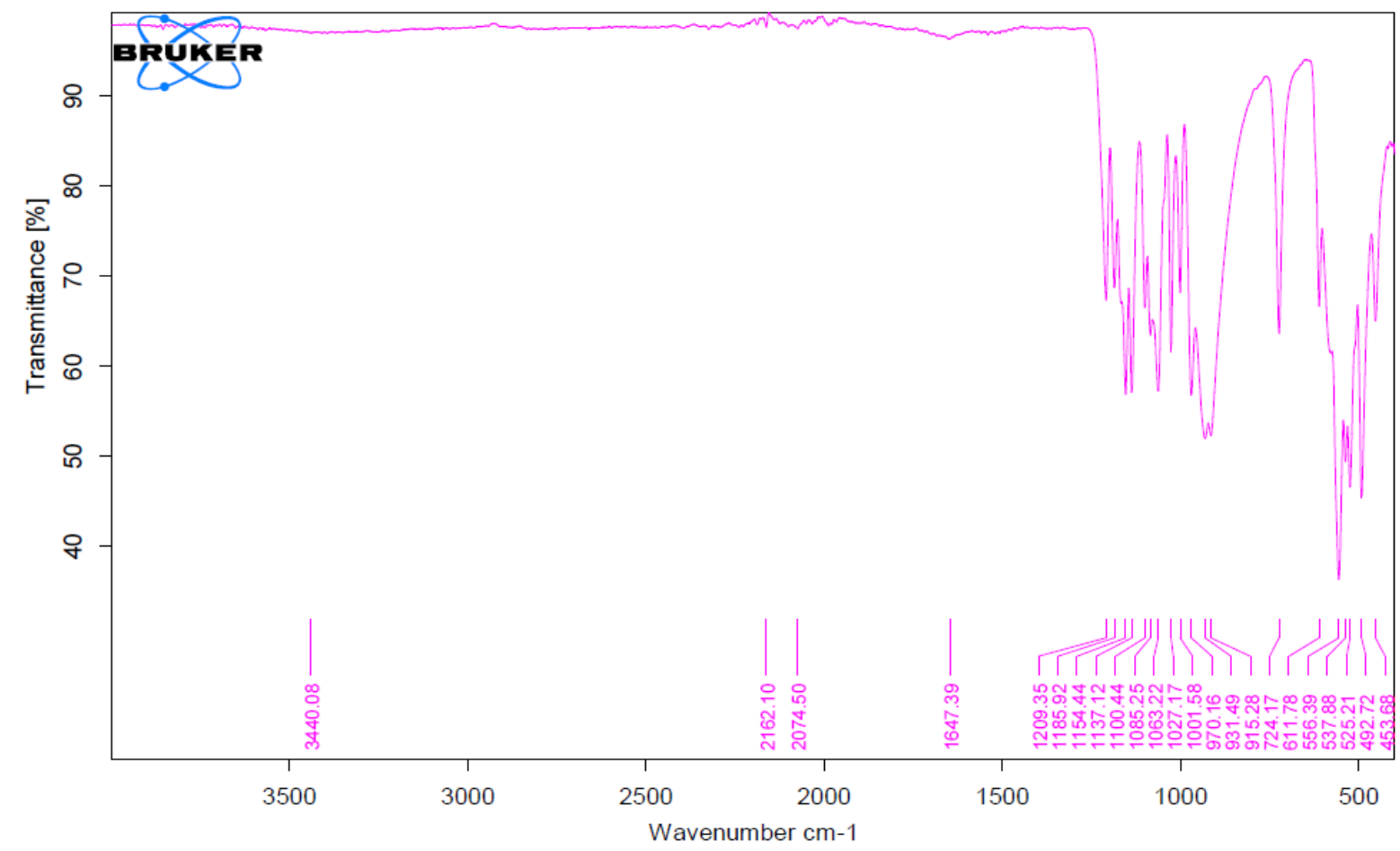

Figure 3: FTIR for Eggshell hydroxyapatite

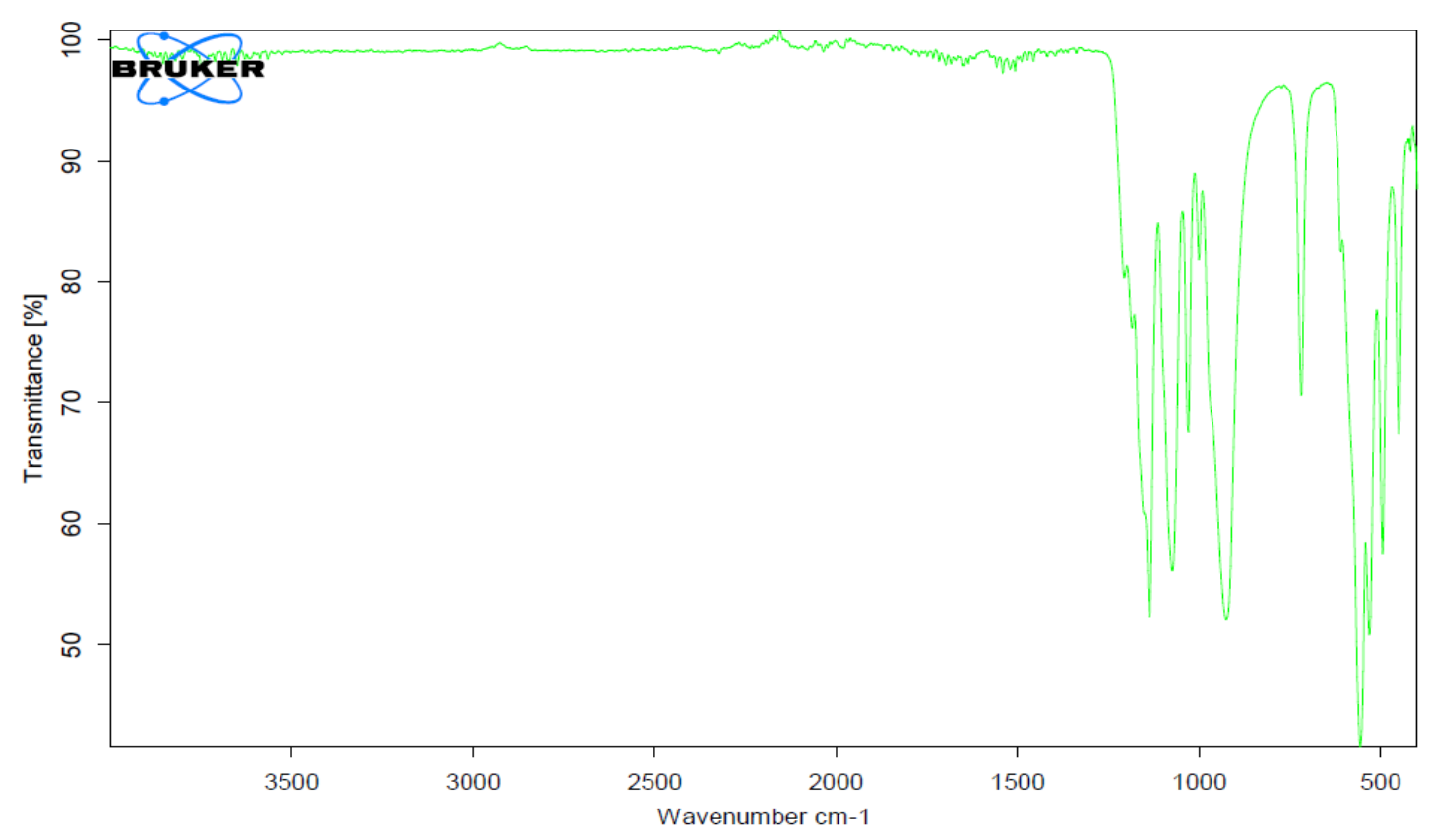

Figure 4: FTIR for Seashell hydroxyapatite.

\section{2-Estimation of the Chemical Structure}

Silver nitrate solution was added to an eggshell, seashell and control H.A powder, A yellow precipitation was formed in eggshell and control H.A and less yellowish when added on seashell H.A. 
Banan N. Alhussary et al......

\section{Histological Evaluation and Biocompatibility}

Histopathological examination exposed that all groups showed healing and osteogenesis

\subsection{Control groups}

Micrographs of rabbits mandibular bone from control groups at 30 days: in the site of defect showed incomplete filling of the space with new bone formation, dense connective tissue and ossified callus containing lamellar bone trabecular. (Figure 5).

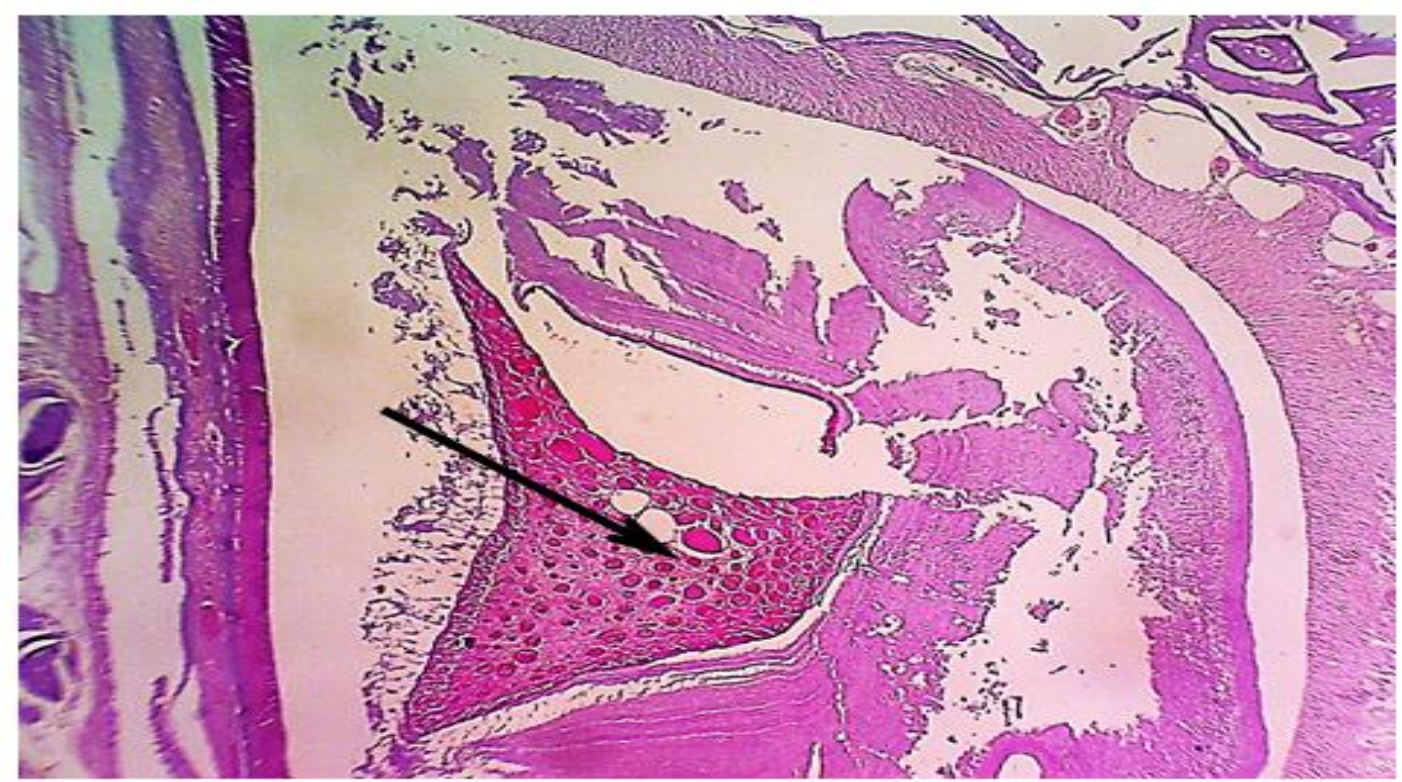

Figure 5:Light micrograph of rabbits mandibular bone from the control group at 30 days showed new bone formation, lamellar bone trabecular $(\rightarrow$. Staining H\&E. Magnification 4 X.

\subsection{Standard Hydroxyapatite groups}

At 30 days: the defect sites showed that moderate space-filling. the highly-dense bone compare with control and eggshell H.A., the size of osteoclast is bigger than that at 15 with few numbers of osteoblast cells, also showed a dense amount of granulation tissue, blood vessels and bone marrow compared with control groups. (Figure 6).

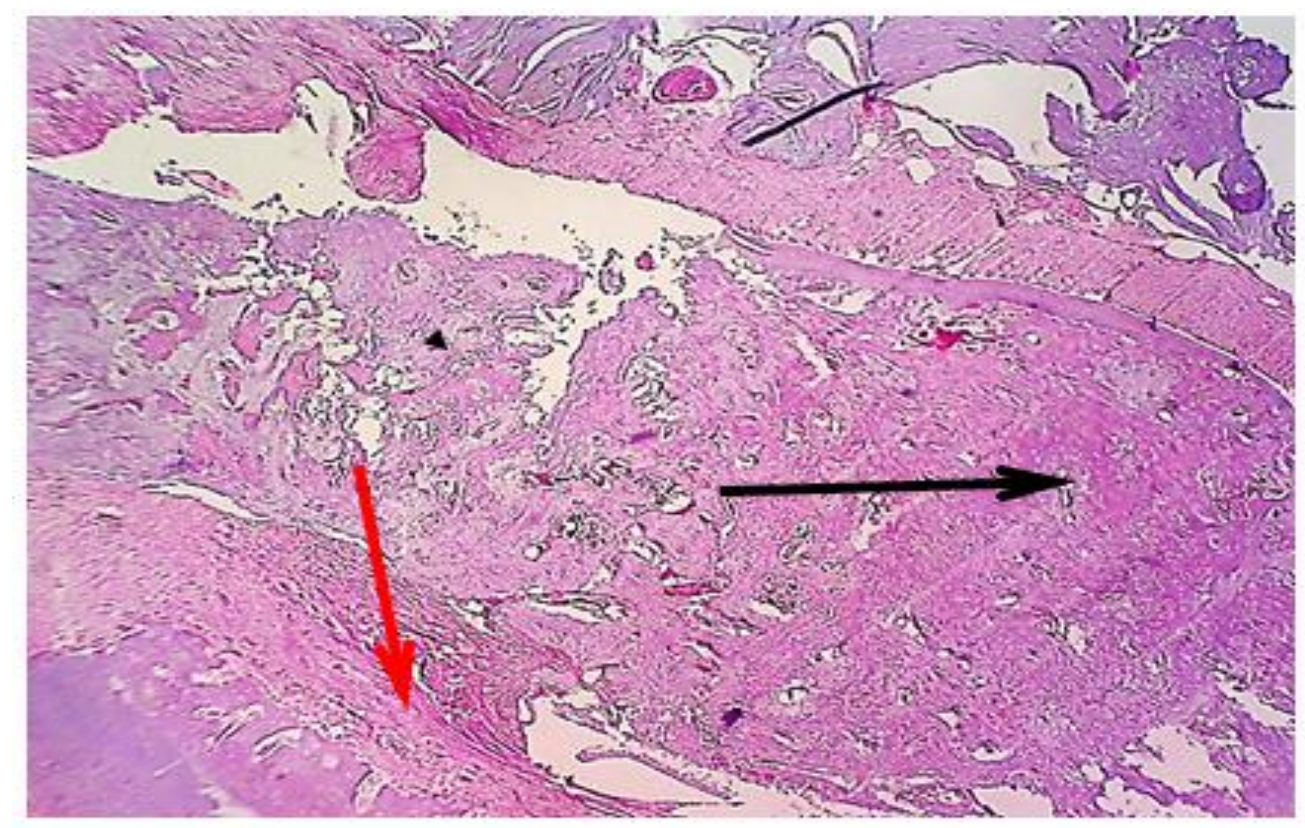

Figure 6: Light micrograph of rabbits mandibular bone from standard H.A. group at 30 days showed dens connective tissue $(\longrightarrow$ ), an abundance of bone lamella $(\longrightarrow)$.Staining H\&E. Magnification 4 X. 


\section{Preparation And Characterization Of Natural Nano Hydroxyapatite ......}

\subsection{Eggshell Hydroxyapatite}

At 30 days: the site of defect showed dense connective tissue with a high amount of lamellar bone trabecular in new bone formation compared with the control group. Also showed congested blood vessels with a high number of osteoblast with few numbers of osteoclast. (Figure 7)

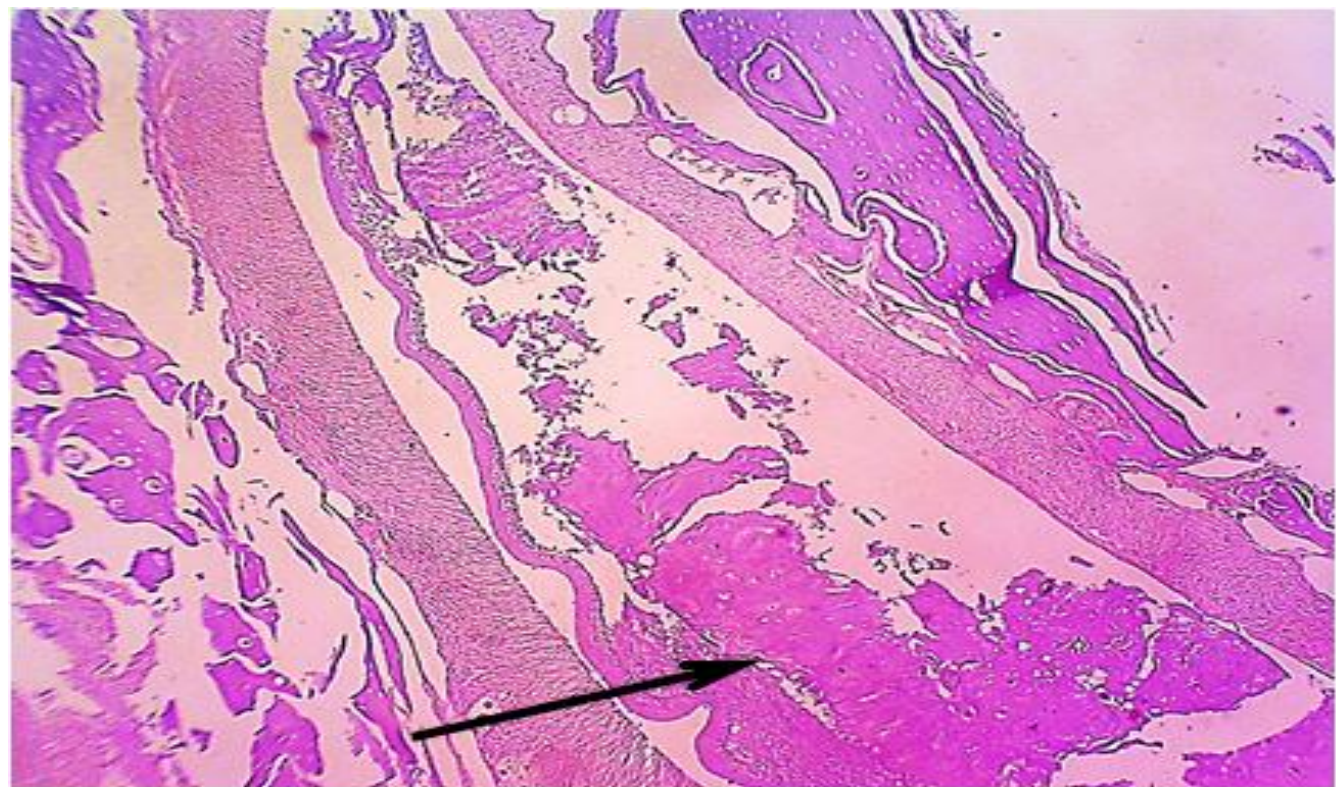

Figure 7: Light micrograph of rabbits mandibular bone from Eggshell H.A. group at 30days showed bone lamella $(\longrightarrow$. Staining H\&E Magnification 4 X.

\subsection{Sea shell Hydroxyapatite groups}

At 30 days: the defect sites showed that moderate space-filling. The highly dense bone compare with control, the size of osteoclast is bigger then that in control, eggshell H.A and standard H.A with few numbers of osteoblast cells, also showed few amounts of granulation tissue, blood vessels and bone marrow compare with control, egg and standard H.A. (Figure 8).

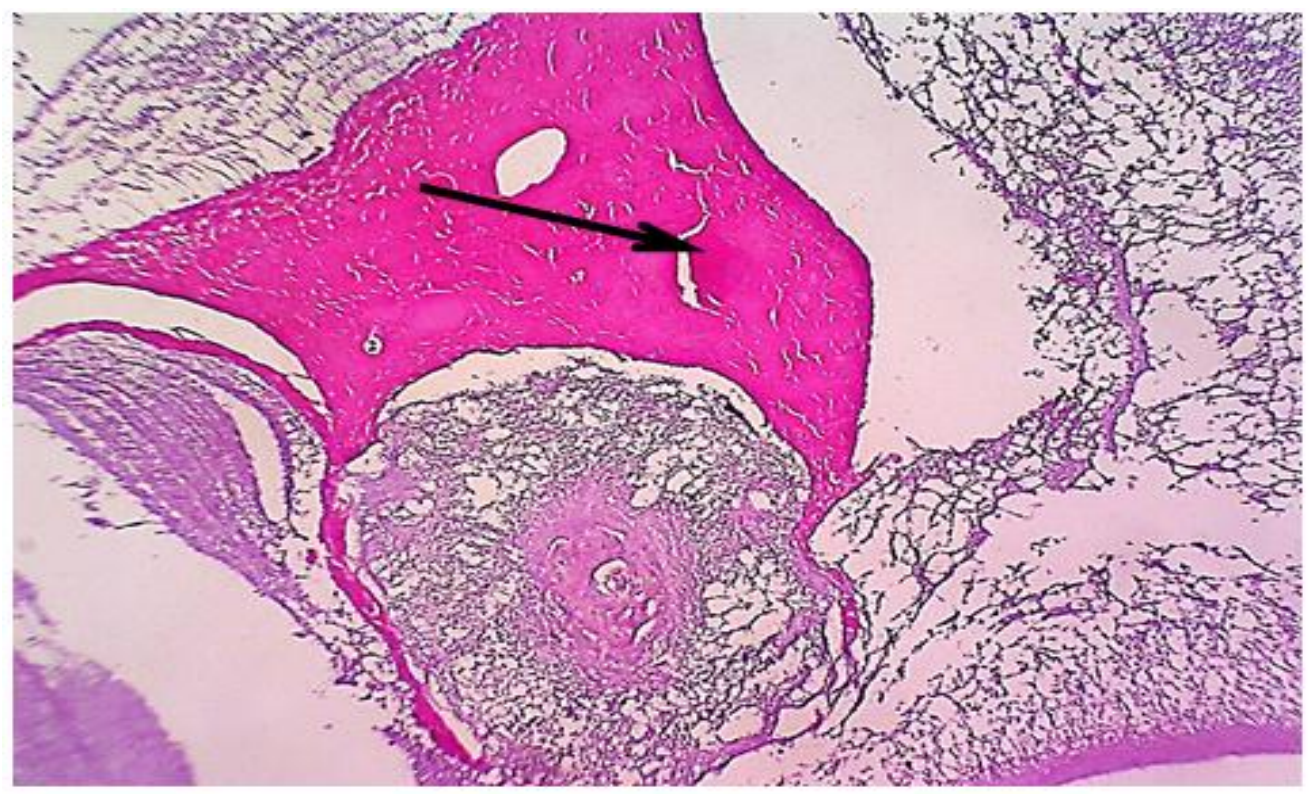

Figure 8: Light micrograph of rabbits mandibular bone from Seashell H.A. group at 30 days showed bone lamella $(\longrightarrow)$. Staining H\&E. Magnification $10 \mathrm{X}$. 


\section{DISCUSSION}

In the Infrared Spectroscopy estimation of important bands, the estimation of hydroxyapatite bands is evaluated by the structure of the powder was analyzed using FT-IR spectroscopy after dried at $100^{\circ} \mathrm{C}$. The IR Spectroscopy for the hydroxyapatite showed some important bands between the region 500$4000 \mathrm{~cm}^{-1}$ which is due to $\mathrm{P}-\mathrm{O}, \mathrm{P}=\mathrm{O}$, and $\mathrm{OH}$ groups. In FT-IR analysis, mainly the peaks for $\mathrm{PO}_{4}{ }^{-3}$ and $\mathrm{OH}^{-}$groups in the hydroxyapatite can be identified These bands confirm the structure of hydroxyapatite. The IR spectrum of raw HA powder is showed. The sharp peak at $925 \mathrm{~cm}^{-1}$ can be explained owing to the $\mathrm{O}-\mathrm{H}$ group deformation. An intense $\mathrm{PO}_{4}{ }^{-3}$ peak appeared at $1030 \mathrm{~cm}^{-1}$. Additional phosphate group bands are found in the region $1000,963,875,639,610$, 566, 531and $450 \mathrm{~cm}^{-1}$, An intense $\mathrm{PO}_{4}^{-3}$ peak appeared at $1030 \mathrm{~cm}^{-1}$. The additional phosphate peaks are found in the region 1138, 495 and $450 \mathrm{~cm}^{1}$. The CO-C peak at $1206 \mathrm{~cm}^{-1}$ and an intense phosphate peak are found at $1037 \mathrm{~cm}^{-1}$. The additional phosphate group bands at $718 \mathrm{~cm}^{-1}$ indicating that :

1. The two compounds showed approximately the same IR spectrum.

2. The location of bands is approximately the same in the two compounds.

Estimation of the Chemical Structure: Silver phosphate is formed as a yellow precipitate by the reaction between a silver nitrate solution, orthophosphate; This compound is dissolved by nitric acid, or by ammonia. By this chemical test we confirming the presence of phosphates in the chemical structure of both materials.In the Surgical procedure, an animal model was chosen for the ease of handling, and because rabbits reach skeletal maturity at around 6 months of age, the rabbit has a faster bone turnover (Calciolari et al, 2017).

Histological examinations were performed to evaluate bone regeneration. The histological findings in the present study indicated that the defect areas of the experimental animals in all groups showed various amounts of new bone formation by HA, this result may be explained by opinion mentioned by Hiratsuka $\boldsymbol{e t} \boldsymbol{a l}$, (2010) that The process of bone formation onto the bone surface using a hydroxyapatite/collagen bone. The histological finding of eggshell HA treated groups at all-time post-operation filled the bone defect compared to the control groups, this result may be related to the eggshell which is accelerated the bone formation this result may be explained by opinion mentioned by Salama et al, (2019) that the eggshellbased graft powder, is a biocompatible material which has the potential to enhance new bone formation. The eggshell HA which used calcium phosphate in both rabbits and humans this result may be explained by the opinion mentioned by Dadhich $\boldsymbol{e t}$ al, (2016) that the eggshell-derived multiphasic calcium phosphate scaffold displayed improvement in the mechanical properties with higher porosity and osteoinductivity in the bone-graft application.

The histological finding of seashell HA treated groups at all-time post-operation filled the bone defect and well fitted to the bone cut ends, compared to the other groups, this result may be related to the seashell HA that enhanced bone formation and the result may be explained by opinion mentioned by Orman $\boldsymbol{e t} \boldsymbol{a l}$, (2019) that the seashell HA has ideal pore size and properties supporting bone tissue growth and cell proliferation. Therefore, it can be a good candidate for clinical applications owing to low production cost and natural-biological origin.

Results from histological examination of inflammatory cell infiltrate at the site of the bony defect were found only on the control group while there is no infiltration of inflammatory cells in all groups of HA in all three-time intervals. The inability to detect inflammatory cells in the HA group in the first week could be due to the anti-inflammatory effect of the material used, thus it didn't evoke any unexpected inflammatory response and consequently, no excess inflammatory cells accumulated at the site of the operation. this result may be explained by the opinion mentioned by Shapovalova et al., (2016) that the HA can stimulate the release of anti-inflammatory cytokines that indicates the presence of potential antiinflammatory properties.

\section{CONCLUSION}

The present study concluded that the ability to prepared hydroxyapatite powder from eggshell and seashell and convert them in nanosize by prepared by precipitation method and study the FTIR Spectroscopy for the eggshell and seashell hydroxyapatite powder to show the two compounds and The location of bands and Easy to use as a bone substitute with unlimited availability.

\section{ACKNOWLEDGMENT}

The authors are very grateful to the University of Mosul , College of Dentistry for their provided facilities, which helped improve the quality of this work.

\section{REFERANCES}

ANCHANA D and PRIYA P. 2016. Synthesis and Application of Hydroxyapatite Bioceramics from Different Marine Sources. Journal of Research in Environmental and Earth Science, 2(11): 7-15. 
CACCHIOLI, A., SPAGGIARI, B., RAVANETTI, F., MARTINI, F. M., BORGHETTI, P. \& GABBI, C. 2006. The critical-sized bone defect: a morphological study of bone healing. Ann. Fac. Medic. Vet. di Parma, 26, 97-110.

CALCIOLARI, E., DONOS, N., \& MARDAS, N. 2017. Osteoporotic animal models of bone healing: advantages and pitfalls. Journal of Investigative Surgery, 30(5), 342-350.

CLAUDIO L. DE CASTRO, BRAIN S. 2005. Mitchell Department of Chemical Engineering, Tulane University, New Orleans, Louisiana, USA, ( chapter one).

DADHICH, P., DAS, B., Pal, P., SRIVAS, P. K., DUTTA, J., RAY, S., \& DHARA, S. 2016. A simple approach for an eggshell-based 3D-printed osteoinductive multiphasic calcium phosphate scaffold. ACS applied materials \& interfaces, 8(19), 11910-11924.

DOROZHKIN, S. V. 2009. Nano dimensional and Nanocrystalline apatite and other calcium orthophosphates in biomedical engineering, biology, and medicine. Materials, 2(4), 1975-2045.

FARA, A.; KHALIS, A. N.; BIN YAHYA, M. A., and ABDULLA, H. Z. 2015. Preparation and Characterization of Biological Hydroxyapatite (HAp) Obtained from Tilapia Fish Bone. Advanced Materials Research, 1087(1):152-156.

HIRATSUKA, T., UEZONO, M., TAKAKUDA, K., KIKUCHI, M., OSHIMA, S., SATO, T., ... \& MORIAMA, K. 2020. Enhanced bone formation onto the bone surface using a hydroxyapatite/collagen bone-like Nanocomposite. Journal of Biomedical Materials Research Part B: Applied Biomaterials, 108(2), 391-398.

KHANDELWA, H. and PRAKASH S. 2016. Synthesis and Characterization of Hydroxyapatite Powder by Eggshell. Journal of Minerals and Materials Characterization and Engineering, 4(02): 119.

MAHA A.Al-MURAD, MA'AN M. NAYIF, AMER A. TAQA, 2019. The Effect of incorporation Hydroxyapatite nano-particles on Shear Bond Strength of Self -Adhesive Resin Cement, acceptance for publication journal of oral research.

NANCI, A. 2017. Ten Cate's Oral Histology-E-Book: Development, Structure, and Function. Elsevier Health Sciences.

ORMAN, Z., YUSEL, S., SAHIN, Y. M., GUNDUZ, O., \& OKTAR, F. N. 2019. Bioactivity of Hydroxyapatite Produced from Sea Snail Turritella Terebra. Acta Physica Polonica, A., 135(5).

PARK, J. B. \& BRONZINO, J. D. 2003. Biomaterials principles and applications. (Eds.), Boca Raton, London, New York, Washington DC, CRC Press.

RIPAMONTI, U.; CROOKS, J.; KHOLI, L. and RODEN, L. 2009. The induction of bone formation by coral-derived calcium carbonate/hydroxyapatite constructs. Biomaterials, 30(7): 1428-1439.

SALAMA, R., KHASHABA, M., \& El ROUBY, D. 2019. Histomorphometric evaluation of a Nano-sized eggshell-containing supplement as a natural alloplastic: An animal study. The Saudi dental journal, 31(3), 375-381.
SHAPOVALOVA, Y., LYTKINA, D., RASSKAZOVA, L., ZHUK, I., GUDIMA, A., FILIMOSHKIN, A., ... \& KZHYSHKOWSKA, J. 2016. Preparation of biocompatible composites based on poly-Llactide/hydroxyapatite and investigation of their antiinflammatory activity. In Key Engineering Materials (Vol. 683, pp. 475-480).

SZCZES, A., HOLYSZ, L., \& CHIBOWSKI, E. 2017. Synthesis of hydroxyapatite for biomedical applications. Advances in colloid and interface science, 249, 321-330.

TANGBORIBOON, N.; KUNANURUKASAPONG, R. and SIRIVAT, A. 2012. Preparation and properties of calcium oxide from eggshells via calcination. Materials Science-Poland, 30(4): 313-322.

TRON, A. C. 2016. Decellularized whole organs as vascularized bioscaffolds for bone tissue engineering (Doctoral dissertation, Technische Universität Münchn.

How to cite this article:

Banan N. Alhussary, Ghada A. Taqa, and Amer A. Taqa.2020. Preparation and Characterization of Natural Nano Hydroxyapatite From Eggshell and Seashell and Its Effect on Bone Healing. Journal of Applied Veterinary Sciences, 5(2): 25-32. DOI:HTTPS://DX.DOI.ORG/10.21608/JAVS.2020. $\underline{85567}$ 